\title{
The Reform and Exploration of Electrical and Electronic Practice Teaching Mode
}

\author{
HUANG Rui \\ Center of Training \& Experimentation \\ Shanghai Second Polytechnic University \\ Shanghai,China \\ e-mail: huangrui@sspu.cn
}

\author{
ZHANG yonghong \\ Center of Training \& Experimentation \\ Shanghai Second Polytechnic University \\ Shanghai,China \\ e-mail: yhzhang@sspu.cn
}

\begin{abstract}
The fundamental target of higher education is to train personnel meet the needs of the development of modern society, Practice teaching is an important part of higher education personnel trainin for practical ability and innovation ability . In electrical and electronic practice teaching, for example, the paper discusses the practical teaching mode in higher education reform in some of the problems, and put forward the corresponding countermeasures.
\end{abstract}

Keywords- Engineering education;Electrical and electronic practice teaching;Ability training.

\section{INTRODUCTION}

With the transformation of economic society and the internationalization of higher education development, China's higher education develops from the elite to the popularization and universal. The fundamental target of higher education is to train personnel meet the needs of the development of modern society ${ }^{[1]}$. The improvement of practical ability and innovation ability is crucial for the personnel training. Facing the current increasingly outstanding contradiction which is university students are difficult to employment and companies are difficult to recruit suitable talents, the intensification of the process of global integration, Countries around the world integrate in various fields, such as politics, economy, culture, science and technology. Colleges and universities must reform the existing practice teaching mode and Strengthen the concept of engineering education, With project implementation as education carriers, introduce cross-courses ,cross-school, cross-field practice teaching mode, Adhere to the developmental road that industry, academia and research is combined with. To train and bring up innovative compound talents with Good Humanities, natural science literacy and with Some international perspective and the ability of crosscultural communication, competition and cooperation .

Electrical and electronic practice teaching including electrical and electronic experimental teaching and electrical and electronic practice teaching, which is an important part of teaching system in higher education and an important part of the personnel training goals. Hence, Shanghai municipal electrical and electronic practice base construction is as an opportunity for the research group. Taking into account the reason that diversification of students in our school and mainly training compound, application-oriented talents. We deepen teaching reform of electrical and electronic practice,
Focus on the cultivation of students' experimental ability, practical ability, innovation abilit.

\section{CurRent PRoblems in PRACTICE TEACHING AND IINNOVATION ABILITY TRAINING}

\section{A. Practice teaching adopt the traditional single duck- stuffing teaching mode}

Practice teaching uses more demonstration teaching methods, students' innovative thinking and practical ability is poor. By the influence of Chinese traditional education quality view of knowledge reserve type, taking it as evaluation index that students have the number to master theoretical knowledge and academic ability levels. It is not included into the scope assessment of education quality in colleges and universities that students' non-intelligence factors development, practical ability and innovation ability.

\section{B. Do not pay enough attention to the practice teaching} and let teaching content set become a mere formality

College students and young teachers is influenced by the traditional idea of subject education, Lack of knowledge on the importance of practice teaching in the talents cultivation about Innovation, creativity and entrepreneurship. Furthermore, there is too much emphasis on the education of basic knowledge in the teaching mode and curriculum, Causes the student have not good training of practice ability, separate higher education from the actual production and employment needs, Cause graduates have good scores but low qualities and be difficult to obtain employment.

\section{Practice teaching content and teaching system is Closure, delay and passive}

Most of the college practical teaching program is attached to the theoretical teaching and lags behind the development of science at the forefront of technology, There is single contents and outdated equipment, Lack of integration of courses, subjects, fields, etc. Thus, Cause some problems that students have few hands-on opportunities and passive learning, are not active to the practice teaching. 


\section{EXPLORATION OF PRACTICETEACHING AND CUltivation OF INNOVATIVE ABILITY}

\section{A. Updating and optimizing experimental teaching contents}

How to inspire students to use the knowledge to find problems, analyze and solve problems, How to cultivate students' experimental ability, innovation ability and comprehensive quality, How to guide the students in the experiment put forward new ideas and new perspectives, How to stimulate students' innovation consciousness, How to help students master the basic methods of scientific research, How to encourage students to actively participate in a variety of technological innovation activities and electronic competition and acquire new knowledge and technology from it, Which has become important and difficult issues about Deepening reform of electricelectronic practice teaching and improving the quality of teaching ${ }^{[2]}$. In order to effectively improve the quality of electrical and electronic experiment teaching, the electrics and electronics experiment teaching content of the tradition needs to be updated and optimized. According to the experimental teaching goal and students' current level of knowledge, the electrical and electronic experimental teaching content is divided into two main modules, including basic experimental module and comprehensive design experiment module. Basic experimental courses and theory course are alternately taught, Comprehensive design experiment courses are taught in a variety of alternative teaching activities and electronic science and technology innovation competition.

1) Diversified teaching promote the teaching experiments in different levels

Basic experimental courses include circuits, analog electronics, digital electronics and electrotechnics, it is closely related to the theoretical teaching and supplement each other, it is an important course to cultivate students' experimental ability. The content of basic experimental courses should be changed from single verification experiment to multi-level verified experiments, comprehensive experiments, design experiments and simulation experiments. Verification experiment provides specific experimental content, trains students to master the basic instrument function and use method, master the basic experimental skills and methods, deepens understanding of the related theory and technology, the theory class is moved to the laboratory can achieve the best effect ${ }^{[3]}$. The comprehensive experiment use existing laboratory equipment device to finish the experiments related to the course comprehensive knowledge, focus on flexible application of experimental knowledge, methods, and skills, Mainly let students be familiar with instruments and equipment and the team cooperation ability. Design experiments train students independently designed experiments according to the specific requirement, pay attention to arouse students initiative and enthusiasm, guide the students to use the knowledge to find problems, analyze and solve problems in the process of experiments. Simulation experiments mainly relying on design experiment to cultivate students ' ability to use modern design tools, In order to extend to the outside of courses, arouse the curiosity of the students. It can strengthen students' autonomous learning awareness and effectively cultivate students' innovation ability, encourage students to put forward new ideas based on experiments.

Multi-level reform and innovation in the experimental teaching content provide a platform for teachers to teach students in accordance with their aptitude, also provide independent experiment, personality development space for different majors, ability, interested students, are suit to cultivate the experimental ability of students of different levels ${ }^{[4]}$.

2) The comprehensive design experiments cultivate students' cooperation and innovation ability

Cooperation and innovation is thoughts and actions aimed at improving the team's innovation spirit and practical ability education. Electrical and electronic comprehensive design experiments course is based on curriculum design, also is integrated into a variety of alternative teaching activities and electronic science and technology innovation competition. Design and development for engineering application train students' ability of design, integration, testing, comprehensively improve students' effective use of knowledge and new technology in circuit level comprehensive design ability and system-level development and application. For comprehensive designing experiments playing their rightful role in the cultivation of students ' ability, There should be both the conventional circuit design and the circuit design of programmable device and Related engineering problems in the content of the design. On the basis of the exploration and the discovery, the comprehensive design experiments consolidate and develop the learning outcomes and achieve the teaching aim about organic combination of theory with practice and make the students' cooperation ability and innovation ability greatly improved.

\section{B. Improvement of experimental teaching methods and experimental teaching methods}

1) The heuristic teaching to improve students' ability to solve practical problems

The heuristic teaching is refers to the teacher according to the teaching goal, from the age of the students, psychological characteristics, knowledge base, cognitive structure of reality, using various methods to guide the students to be lively and vivid, active thinking, to enable them to take the initiative to acquire knowledge, develop intelligence teaching method ${ }^{[5]}$. It is an active two-way teaching method. In electrical and electronic teaching course, focus on the cultivation of students' ability, mainly experimental guidance. Focus on explaining the considerations of experiment and primary content of the new 
instrument and method of use, the main content of the key and difficult. When students encounter problems, teachers do not give the answer directly and indirectly prompted to boot, training students to think and use the knowledge to identify problems, problem analysis and problem-solving skills.

2) Cultivation of students ' autonomous learning ability and innovative consciousness

In electric and electronic experimental teaching process, should reflect the student-centered and teacher-led idea of experimental teaching to cultivate students ' ability to target, don't just tell students ' experimental results, but to the students master the experimental process. In previous experiments, experimental materials are specified on the books and prepared by teachers before class. During the experiment, students complete steps in accordance with the regulations. In this process, students became mechanical operators without thinking. This teaching does not give students the space and flexibility of thinking, inhibit students' active participation and independence of thinking. Modern education is to guide students ' autonomous learning. Therefore, in conjunction with the actual teach students some basic experimental research methods, then let them take the initiative to find information and clarify the experimental principle, choose the experimental materials and experimental methods. In this way, it can make the students deepen the understanding of the whole process of the experiment, improving the efficiency of experimental courses; also can cultivate their interests and expertise. Teachers should also develop some comprehensive experiment of experimental interest can stimulate students' interest in experiment; arouse students initiative, to cultivate students' innovation consciousness and practical ability. Students follow the completion of the pilot requested access to information - research design - computer simulation - components Selection - implementation experiment. Through knowledge, interest, ability, quality education in an experimental process, cultivate students' autonomous learning ability, innovation ability.

\section{Strengthening Practical Training}

Electrical and electronic practice teaching is an important part of colleges and universities of engineering practice teaching, is to train for the first line has the strong practice ability and innovation ability, applied talents and a few elite type of talent the indispensable important segment. Relative to the theoretical teaching, electrical and electronic practice teaching is more intuitive, comprehensive and innovative features. According to this characteristic, in the process of electrical and electronic practice teaching, emphasize on students' engineering consciousness, engineering practice ability and innovation ability. Strengthen the practice teaching in electrical and electronic practice teaching is to improve teaching quality, improve the teaching effect. Establishing and perfecting the practical teaching base are the basis of cultivation of students ' abilities; construction and reform of practical teaching content are the guarantee of training students ' ability.

1) Constructing and reforming the training content, training engineering practical ability

In order to effectively improve the quality of electric and electronic practical teaching, highlighting the cultivation of students ' ability of engineering practice, the original practical teaching content is supplemented and sifted. According to the objectives of practical teaching , teaching content is set into two modules: understanding practice and basic training module, engineering application and innovation training module. The module before is the basic skill training, students will master the basic knowledge and basic skills, establish the concept of electrical and electronic engineering in this module. Cultivating mode is in the form of compulsory courses, with the practice mainly explain supplemented. The specific settings of the projects are divided into two parts: electrical training and electronic training. The electrical parts include: residential power supply circuit, three-phase asynchronous motor relay contactor control, etc. The electronic parts include: digital multimeter , transistor radios, common interesting small home appliances, PCB design and circuit board diagram production and so on. In this part, students can identify the diagram, assemble, test, debug product independently according to electrical and electronic circuit diagram and process documents, in the end, make the product meet technology requirement.

Engineering application and innovation training module is a part of comprehensive skills training, in this module the content is set with engineering application, research and innovation. Cultivating mode is the way of the content and time open, explanation and self-study combined. Students can choose the projects that are provided by practical teaching base, also can set their own projects, to meet the different needs of different professional and interested students. The engineering application and innovation training provides design and innovative platform for students, and a variety of technological innovation activities and electronic contests are interspersed with it.

Construction and reform of teaching contents of electrical and electronic training is gradual in the practical training teaching process, and provides a platform for teachers to teach students in accordance with their aptitude. At the same time, different professional ability, interested students are provided independent practice, personality development space, in this way it is conducive to cultivate the consciousness of engineering, engineering practice ability and innovative ability of different levels students.

2) Constructing perfect practice base, cultivating engineering practice ability

Establish and improve a more distinctive electrical and electronic practice teaching base in order to promote the quality of electrical and electronic training teaching effectively, and in this base not only a good engineering environment of electrical and electronic practice teaching 
can be created, but also an open individual practice teaching platform can be provided for the students who have interest, hobby and ability. Such as there are two modules in each training location, one is widgets module, which can complete engineering understanding practice and engineering basic training; the other is multifunctional training module (including minimum single-chip microcomputer development system, LCD digital display module, programmable control devices and various kinds of commonly used chip devices, etc. )which can complete engineering application and innovation training. Students can choose, design and debug project which they are interested in by themselves in electrical and electronic practice teaching base. In the same time in order to stimulate students' interest, some basic skills competition and electronic design awards are hosted in the university. Students can communicate, discuss and solve the problem together on the personalized practice teaching platform which is provided by electronic practice teaching bases. This is conducive to promoting fusion between disciplines, and developing the compound and applied talents who have the strong practice ability and innovation ability for the first line.

\section{CONCLUSION}

The most important thing of training qualified personnel is to develop their capacity. According to the characteristics and requirements of electric and electronic practice teaching, to discuss the methods of cultivating students' ability from three aspects which are the improvement of experimental teaching methods, update and optimization of the experimental teaching contents and strengthening of the Practical training. If you use the measures and methods expounded in this paper in the the process of practice teaching, can cultivate students' ability in many aspects, improve the quality of students in a certain extent. But the training of the students' ability is a system engineering, which is not a course can complete alone. In order to training students from knowledge learners into knowledge creators need teachers' persistent efforts.

\section{REFERENCES}

[1] WU Guozhong,Study on Training Plan Reformation Based on CDIO Training Mode. Conference papers:863-865

[2] Zhang YU ,The cultivation of students innovative ability in "Electrical and electronic technology" course teaching. Education and Vocational.2011.6:133-134K. Elissa, “Title of paper if known,” unpublished.

[3] WANG yajun, Reforms of electrical and electronic experimental teaching and cultivation of the students' ability. Laboratory Research and Exploration. 2010,29(3):136-138.

[4] ZHU Zheng-wei, Application and Exploration of CDIO in Sustainable Development of University Experimental Teaching. Research And Exploration In Laboratory.2011.11:131-135

[5] LI Huai,HE Wenting,The Thinking of CDIo Engineering Education Mode. Conference papers:343-346. 